\title{
Risk Behaviors of Street Children in Dhaka City, Bangladesh: A Cross Sectional Study
}

\author{
Tahmina $\mathrm{A}^{1 *}$, Nasrin $\mathrm{H}^{2}$, Mamunur R${ }^{3}$, Bedanta Roy ${ }^{2}$ and Anthony $\mathrm{L}^{4}$ \\ ${ }^{1}$ Obstetrics \& Gynaecology Department, AIMST University Semeling, Malaysia \\ 2 Physiology Department, Quest International University, Malaysia \\ ${ }^{3}$ Department of Medicine, Quest International University, Malaysia \\ ${ }^{4}$ Acting Dean Faculty of Medicine, AIMST University, Malaysia
}

\section{Research Article \\ Volume 3 Issue 2}

Received Date: August 14, 2018

Published Date: September 07, 2018

DOI: $10.23880 /$ oajmb- 16000130

*Corresponding author: Tahmina Afrose, Obstetrics \& Gynaecology Department, Faculty of Medicine, AIMST University Semeling 08100, Bedong Kedah, Malaysia, Tel: 0164017436; Email: drtakeya@gmail.com

\section{Abstract}

Background: In Bangladesh, a lot of children are suffering from human right deprivation of all forms. In addition, they are exposed to the severe form of physical and mental violence at home, in the work place, and the public places. The nature and extent of violence against children are increasing day by day. Dhaka, the capital of Bangladesh. There are about one million street children living and working on the street of Dhaka, Bangladesh.

Objectives: To assess the risk behaviors of the street children in Dhaka city of Bangladesh.

Methods: This cross-sectional descriptive study was carried out to determine the health-related risk behaviors for food, clothing and shelter of street children in Dhaka city. The duration of the study period is January 2010 to June 2010. The target population is street children of Dhaka city. During data collection the researcher able to interview 100 respondents.

Result: Among the respondents, 83 respondents were staying alone in Dhaka city. The reason for staying alone concludes that $19.3 \%$ left their house as they were beaten, for step-parents, $3.6 \%$ did not like to go to school, $14.4 \%$ to earn money, $15.7 \%$ no one to take care, $14.5 \%$ for the poverty, $4.8 \%$ came with friends , $1.1 \%$ came with relative, and $3,6 \%$ for the other reasons. Distribution of the respondents by the habit of eating waste food; showed that $10 \%$ of them do not eat waste foods, $38 \%$ sometimes and $52 \%$ had the habit of eating waste food. Distribution of the respondents by a frequency of physical assaults showed that majority $63.9 \%$ had the history of occasional physical assault, $36.6 \%$ are being often physically assaulted. Among the 53 respondents, $37.7 \%$ had first sexual experience at or below 12 years and $62.3 \%$ at or above 13 years of age. About sexual experience, the majority (53\%) had this experience: among them, all the female street children were included. The study showed that among 53 respondents, $86.8 \%$ were not using the condom. Among the respondents $32.2 \%$ were reported that they were harassed by the unknown person, $16.9 \%$ by police, $11.3 \%$ by friends, and $9.4 \%$ by co-worker $7.5 \%$ by relatives and the rest by others. 
Among the respondent's $27 \%$ of the street children's were engaging in paper/garbage collection, 7\% were kuli, 10\% had taken their job as selling newspaper, 7\% cleaner in WASA and 3\% were engaging in picking other man's pocket. The rest were involved in begging and selling flowers.

Conclusion: The finding of this study suggests that the street children are extremely vulnerable in terms of their health needs and health care-seeking behaviors. So both the Public and private sectors need to take proper steps for providing services for common physical ailments, reproductive health education, and awareness raising and surveillance of STD/HIV/AIDS.

Keywords: Physical and Mental Violence; HIV/AIDS; Street Children; Gender

\section{Introduction}

In Bangladesh, a lot of children are suffering from human right deprivation of all forms. Now a busy city of Dhaka about eight million people and one of the most dense populated cities of the world with a geographical area of 303 kilometer divided into 90 wards. In addition they are exposed to severe form of physical and mental violence at home, in the work place, and the public places [1].

'The United Nation Convention' on the Rights of the Child defined the child as a "human being below the age of 18 years, unless under the law applicable to the child, majority is attained earlier." UNICEF has classified the street children as: Street living, street working; children from street family.

Street children are often termed as "Tokai" in Bangladesh. They are the most vulnerable section of the society. Many children are forced to live and earn on the street due to their distressed situation. Some of them are abandoned children. Most of the street children are immigrants from rural areas mainly for economic reasons. The other reasons are social like uprooted, driven out, abandoned etc. or natural disaster like river erosion. Based on a survey of the Bangladesh Institute of Development Studies the estimated number of street children in Bangladesh to be around 3, 80,000 of whom $55 \%$ are in Dhaka city. Among them $44.2 \%$ are below the 10 years old and $74.3 \%$ are boys while girls account for $25.7 \%[2]$.

In Bangladesh Mortality and morbidity status among the street children has reached on alarming level as a result of hunger and lack of basic health care services [3-7].
Children on the street are engaged in some kind of economic activities ranging from begging to vend. Inhumane treatment is the "norm" for these children. They are extremely vulnerable to sexually transmitted diseases including HIV/AIDS [8]. Worldwide this scenario of street children is alarming but is more prevalent in the poor nation of Asia, Latin America, and Africa.

The major problems of street children are insecure life [4]. Poverty, loss of shelter due to natural calamities are the leading factors that are responsible for a large number of street children get involved in different types of criminal activities [9-13].

Poverty, family disintegration, negligence and social unrest are the leading triggers for a child's life [14] to be the street. Unfortunately these children are not secured despite efforts made by the government and nongovernment organization in ensuring the rights of the children.

\section{Methodology}

This is a cross sectional descriptive study and the duration of study period is January 2010 to June 2010.

The target population is street children of Dhaka city $[15,16]$. According to the United Nation Convention on the Rights of the Child, below the age of 18 years old are children, but in this study only six to eighteen years old children had been selected. The selected areas for interview were intercept points like Moghbazar, Khilgaong, Santinagar, Komolapur station area of Dhaka city. 
Considering the nature of the study and length of time the sample size was limited to 100 , and during data collection the researcher able to interview 100 respondents. The purpose and type of interview were explained to the respondents. Sampling technique was purposive type.

An interview schedule was prepared to guide the researcher during interview. It was pre tested among some children. Almost all questions were structured question except a few open ended questions. The interview was in-depth interview. All the collected data was compiled, tabulated and analyzed by the researcher with the help of SPSS program.

\section{Results}

Based on the survey questionnaire, the authors demonstrated the results through table and charts.

\section{Socio-Demographic Characteristics}

Among the (100) respondents $70 \%$ were boys and $30 \%$ were girls. Majority $(57 \%)$ of the respondents was in (15-17) year's age group of them $35 \%$ were boys and $22 \%$ were girls. Next major group (6-10) years had $42 \%$ street children, among them $32 \%$ were boys and $10 \%$ were girls (Graph 1).

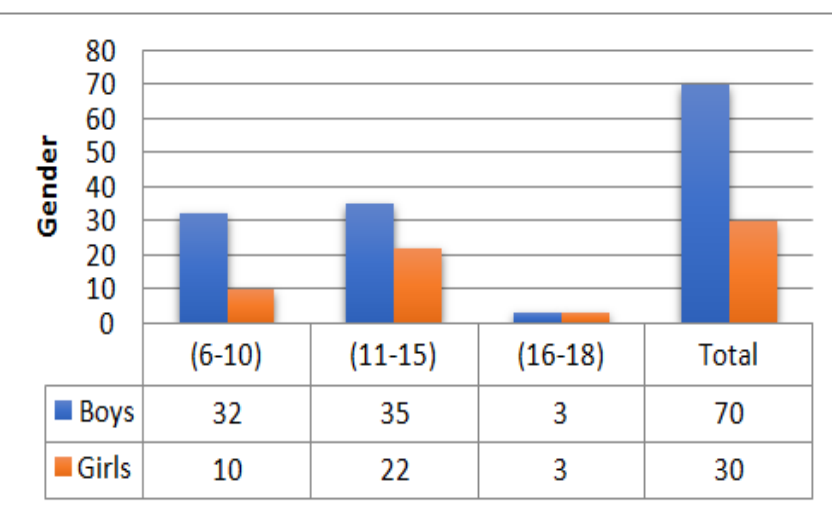

Graph 1: Distribution of the respondents by age in groups and Gender.

Only $6 \%$ respondents were in $(16-18)$ years group, among them 3\% were boys and 3\% were girls.
Among the (100) respondents, majority (53\%) of the adolescent's parents lived outside the Dhaka city, $42 \%$ were in this city. Only $5 \%$ parents are dead (Graph 2).

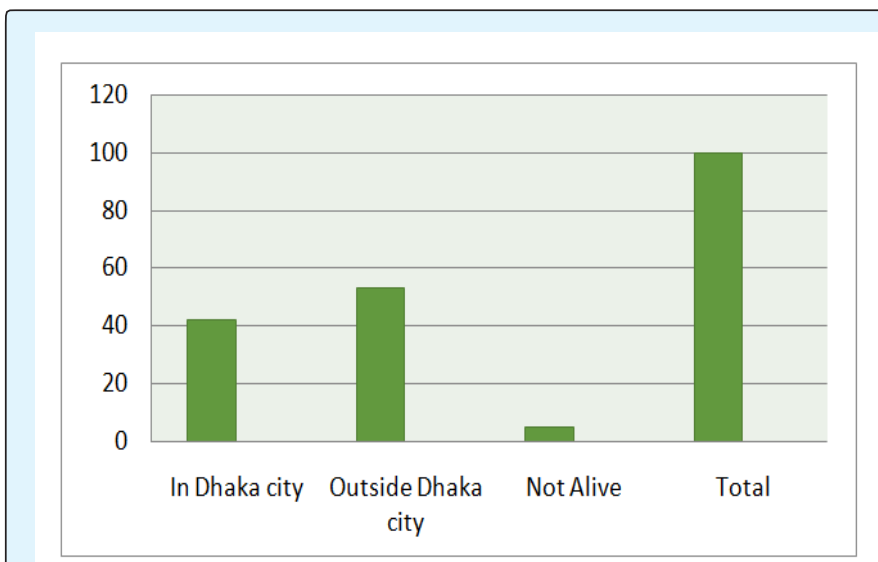

Graph 2: Distribution of the respondents by parent's residential status.

Of the total $60 \%$ live alone, $20 \%$ with others, $9 \%$ with both parents $8 \%$ with mother and 3\% with their brothers (Graph 3).

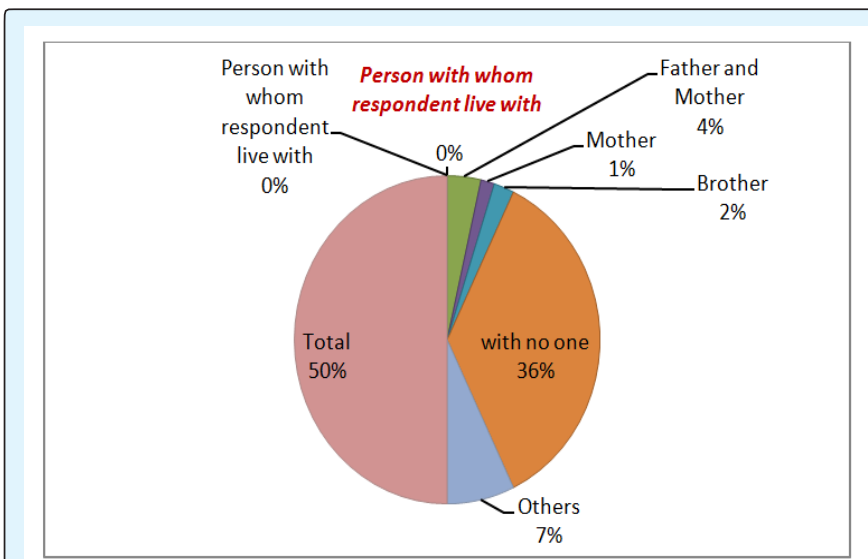

Graph 3: Distribution of the respondents by person they live with.

Among the respondents 83 respondents were staying alone in Dhaka city. The reason for staying alone concludes that $19.3 \%$ left their house as they were beaten, for step parents, $3.6 \%$ did not like to go school, $14.4 \%$ to earn money, $15.7 \%$ no one to take care , $14.5 \%$ for the poverty, $4.8 \%$ came with friends, $1.1 \%$ came with relative, and $3,6 \%$ for the other reasons (Graph 4 ). 


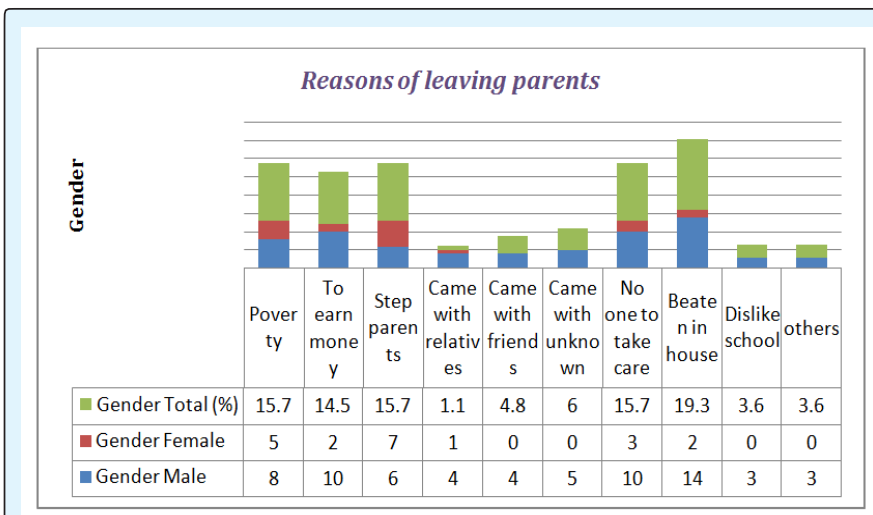

Graph 4: Distribution of the respondents by the reason they left their parents.

Majority (22\%) slept at railway station, $17 \%$ at footpath, $16 \%$ have no specific space for sleeping, $6 \%$ at night shelter, $6 \%$ in the park, $7 \%$ at the launch terminal, $4 \%$ office verandah, $4 \%$ with the family, $2 \%$ in the market place and the rest $1 \%$ in other places (Graph 5).

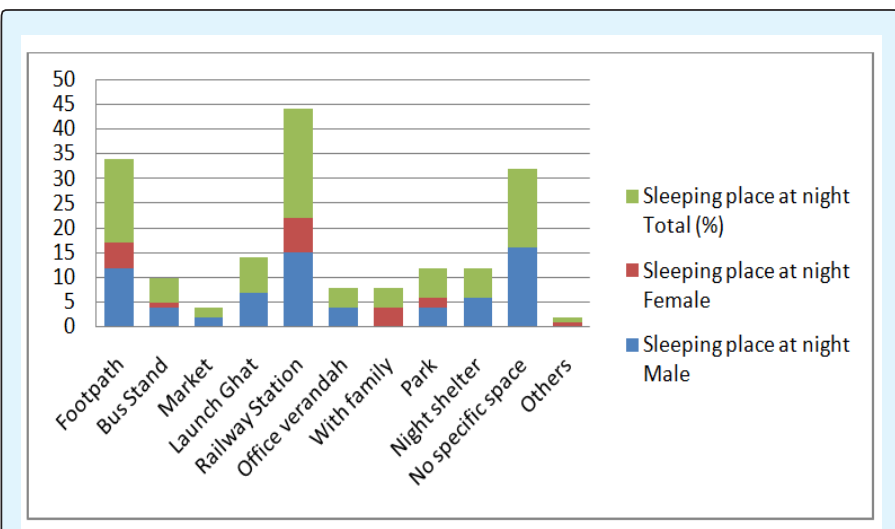

Graph 5: Distribution of the respondents by sleeping status at night.

Among the respondents $46 \%$ worked for 5 to 8 hours, $44 \%$ worked for 1-4 hours and $10 \%$ respondents worked for about 9 hours (Graph 6).

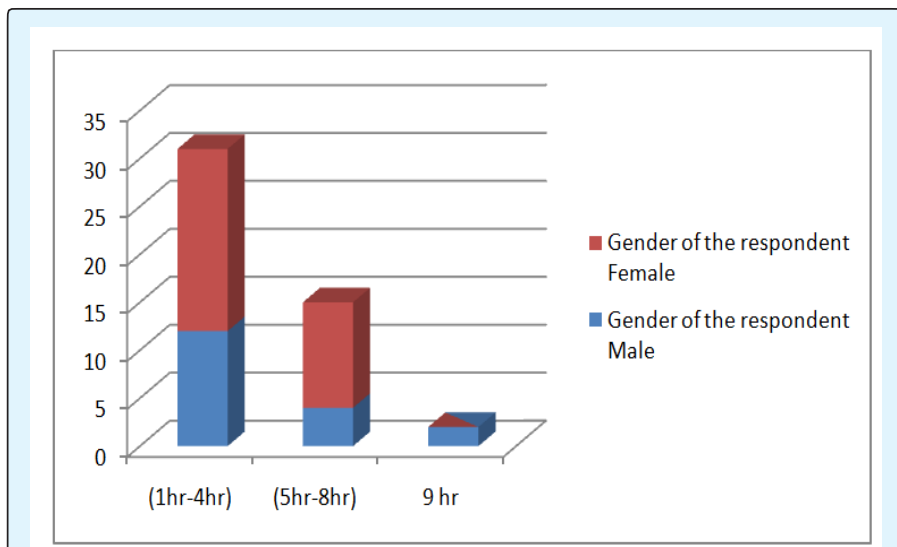

Graph 6: Distribution of respondents by working hours.

\section{Personal Hygiene Related Behaviors}

About $57 \%$ of the respondents do not wash hand before meals, while $18 \%$ do and $25 \%$ is irregular in this habit (Graph 7).

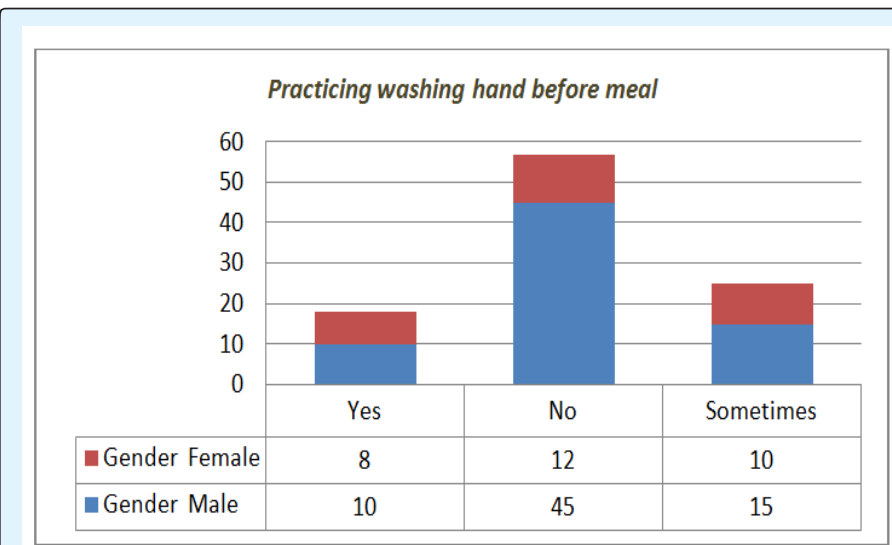

Graph 7: Distribution of the respondents by practicing washing hands before meal.

Washing of hands after toilet, showed that majority $(81.1 \%)$ do not wash hands after toilet, $10.5 \%$ washes hands after toilet and $8.4 \%$ was irregular in this habit (Graph 8). 


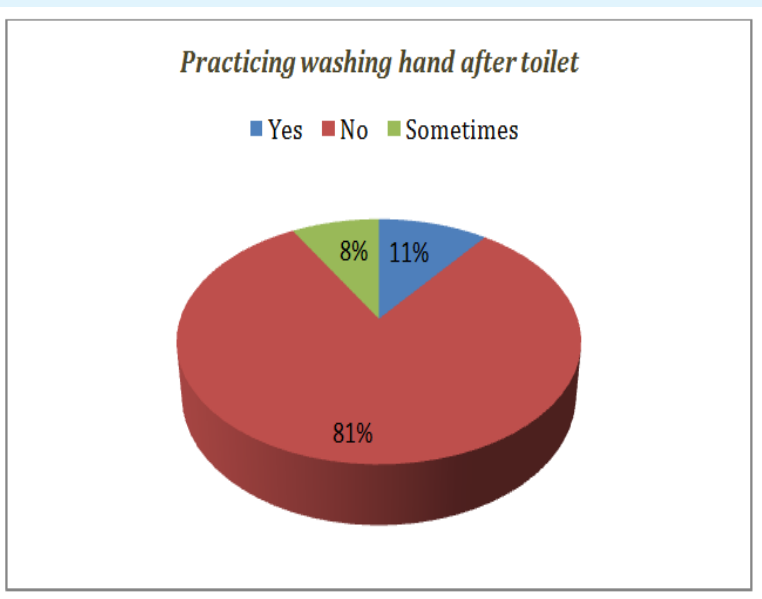

Graph-8: Distribution of the respondents by washing hand after toilet.

Distribution of the respondents by habit of eating waste food; showed that $10 \%$ of them do not eat waste foods, 38\% sometimes and 52\% had the habit of eating waste food (Graph 9).

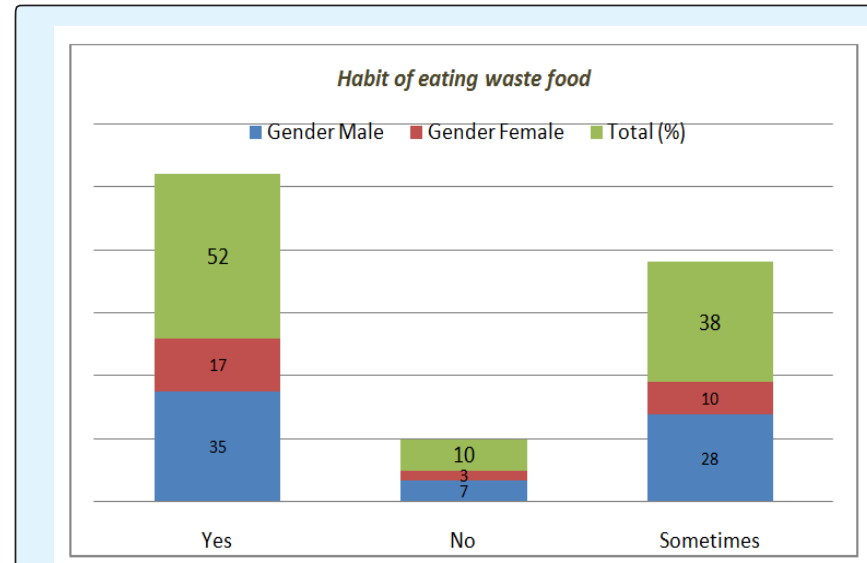

Graph 9: Distribution of the respondents by habit of eating wasted food.

In case of source of drinking water majority (84\%) drink whatever available, only $16 \%$ are being habituated of drinking supply water (Graph 10).

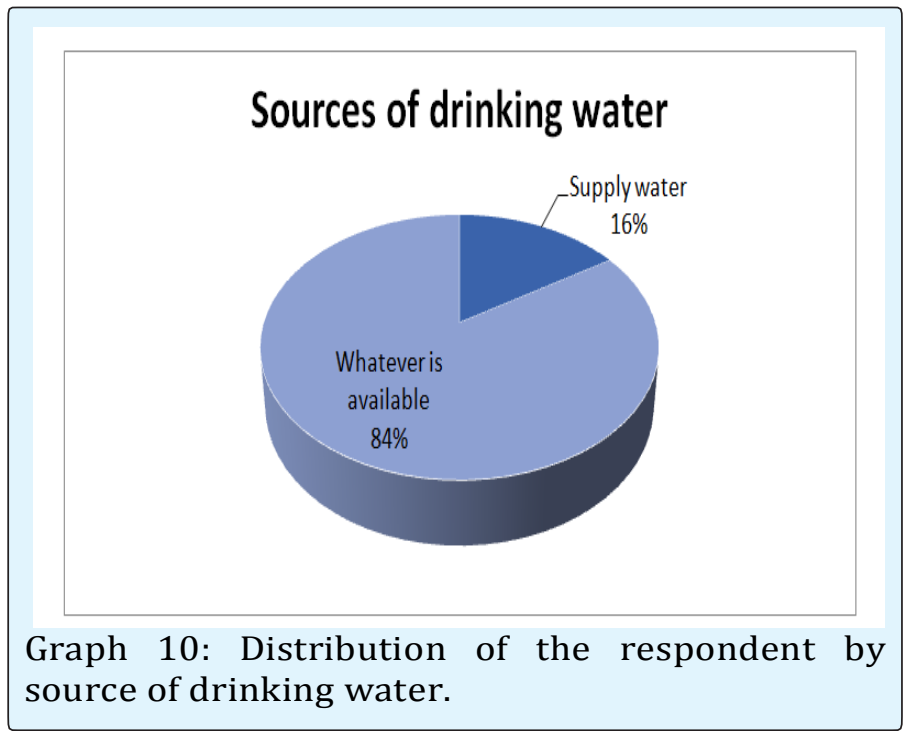

\section{Violence Encountered by them}

Among the respondents $43 \%$ are seldom fighting, $41 \%$ are often involving in fighting and the rest never had the habit of fighting (Graph 11).

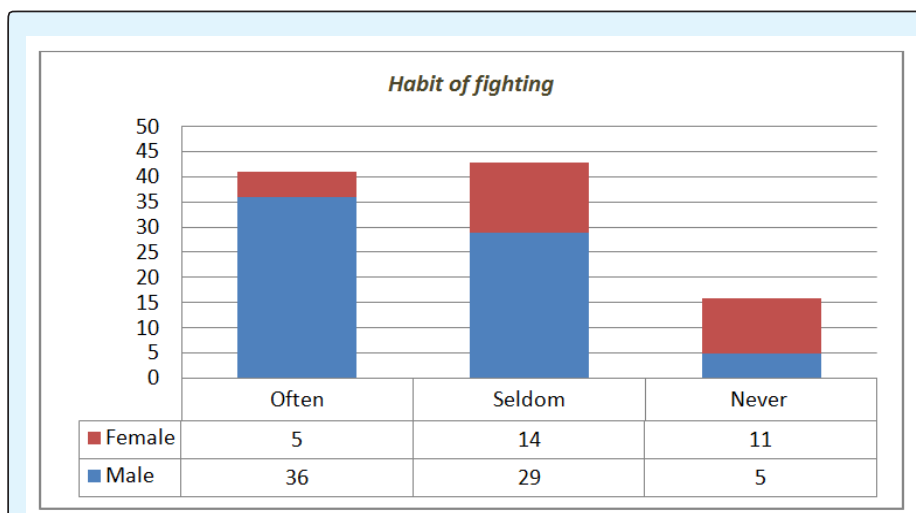

Graph 11: Distribution of the respondent by habit of fighting with others.

Majority (83\%) of the respondents had the history of physical assault, $17 \%$ of them had no history about it (Graph 12). 


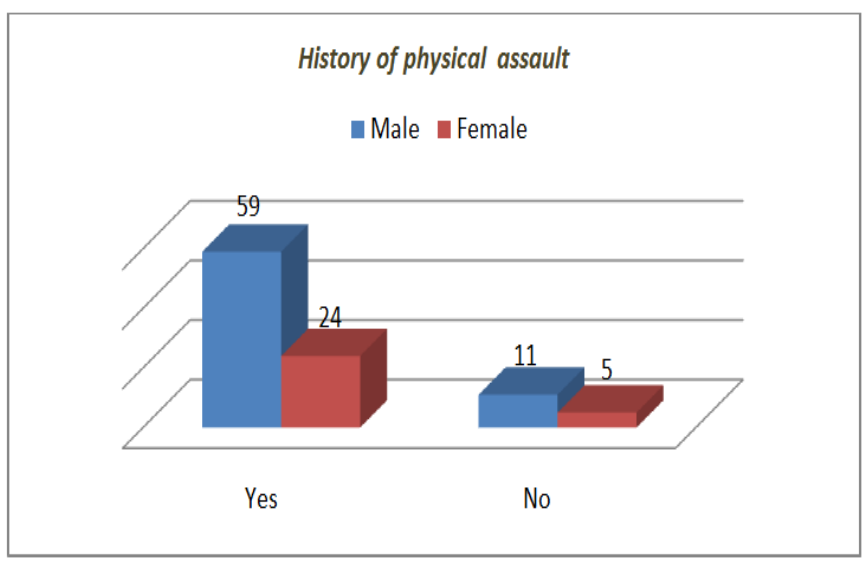

Graph-12: Distribution of the respondent by history of physical assaults.

Among the respondents $38.6 \%$ had the history of assault by policeman, $34.9 \%$ are assaulted by public, $1822.9 \%$ by the 'Mustan'. Among them 24\% was girls (Graph 13).

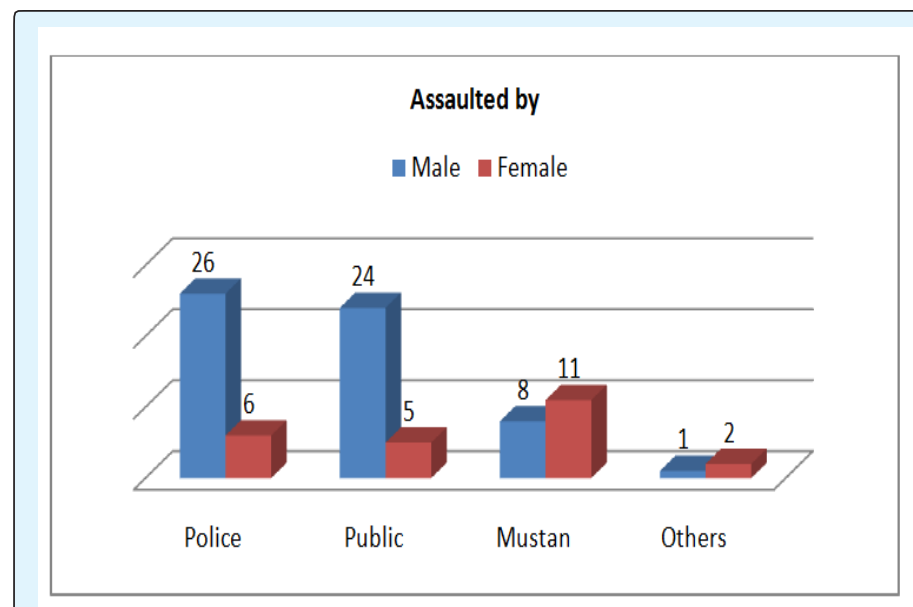

Graph 13: Distribution of the respondent by the person assaulted.

Majority $(65.7 \%)$ of the street children were arrested once, $23.8 \%$ twice and $105 \%$ three or more times (Graph 14).

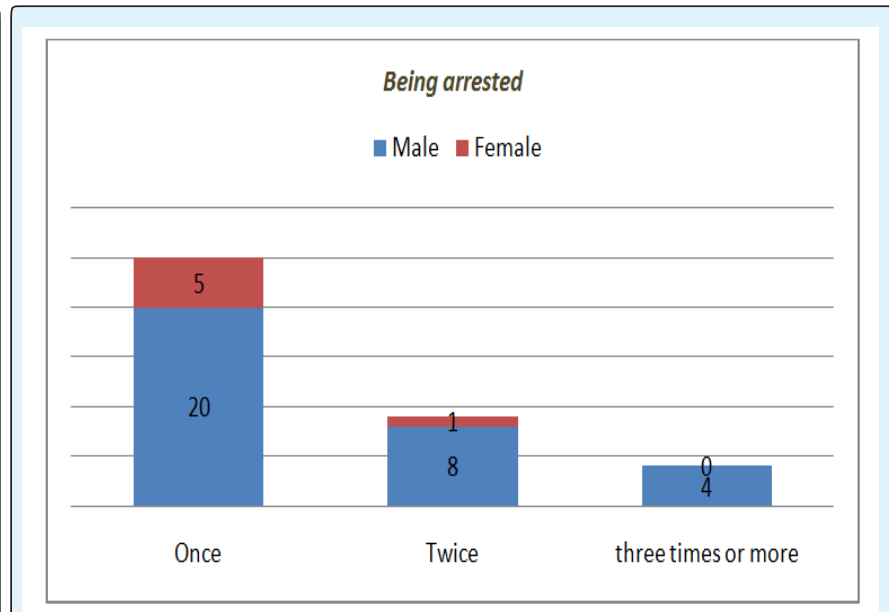

Graph 14: Distribution by history of being arrested.

Of total 57 respondents $28.9 \%$ was arrested for suspect of theft, 15.7 were being arrested for suspect of sexual worker, here majority were girls, $13.23 \%$ for pick pocket, $21.1 \%$ for theft, $7.9 \%$ for fighting and $13.2 \%$ of the other causes (Graph 15).

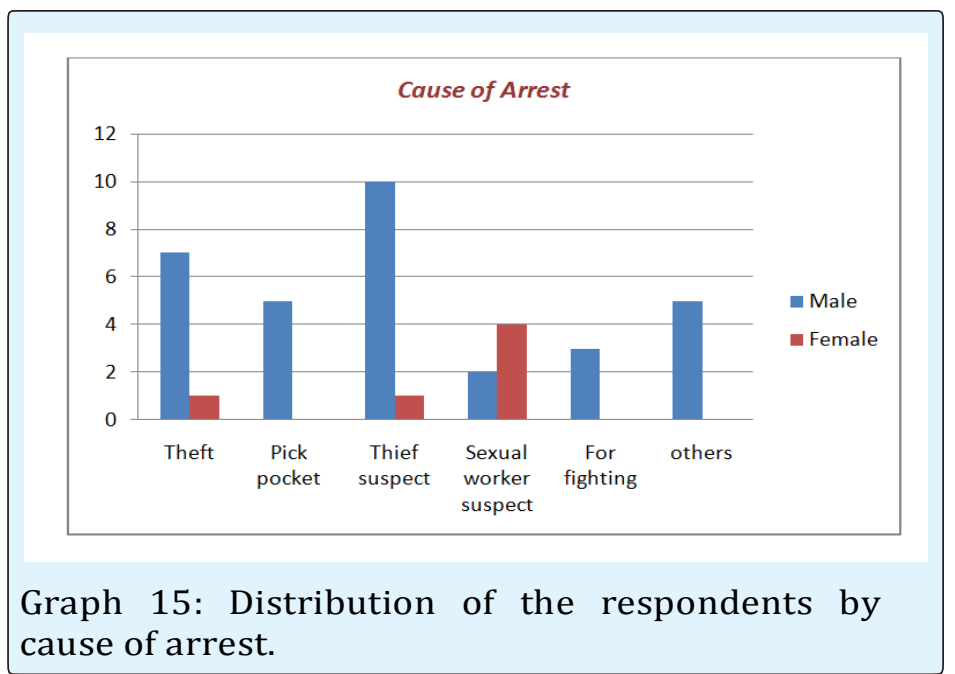

Respondents by taking part in various political activities showed that $56 \%$ had no part in political activities and $44 \%$ responded had taken part in political activities among them all were male (Graph 16). 


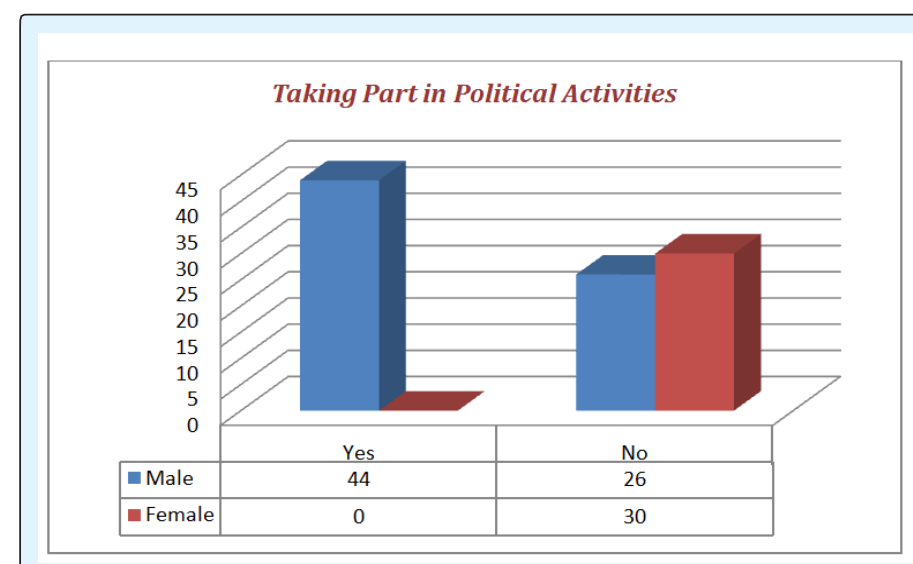

Graph 16: Distribution of the respondents by taking part in various political activities.

Of the total respondents $44 \%$ were regular smoker and majorities were boys, $23 \%$ had the habit of smoking occasionally and 33\% never had this habit (Graph 17).

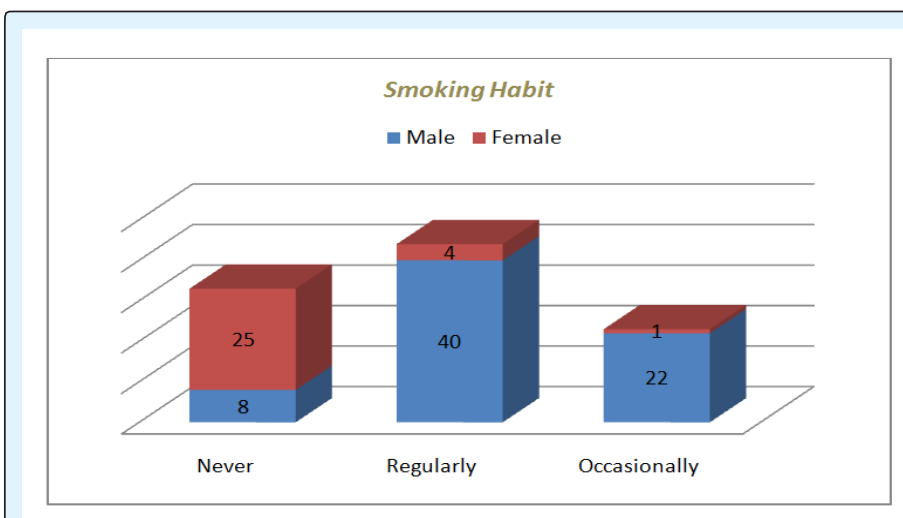

Graph 17: Distribution of the respondents by Smoking habit.

Among them (35.7\%) had it for one month, $(14.3 \%)$ for more than two months and (35.7\%) for two months (Table 1).

\begin{tabular}{|c|c|c|c|}
\hline \multirow{2}{*}{$\begin{array}{c}\text { History of taking } \\
\text { Drug }\end{array}$} & \multicolumn{2}{|c|}{$\begin{array}{c}\text { Sex of the } \\
\text { Respondent }\end{array}$} & \multirow{2}{*}{$\begin{array}{c}\text { Total } \\
\text { (\%) }\end{array}$} \\
\cline { 2 - 3 } & Male & Female & \\
\hline For one month & 12 & 3 & 35.7 \\
\hline Forma two months & 20 & 1 & 50 \\
\hline $\begin{array}{c}\text { More than two } \\
\text { months }\end{array}$ & 6 & 0 & 14.3 \\
\hline Total & 38 & 4 & 100 \\
\hline
\end{tabular}

Table 1: Distribution by duration of taking drug.
Distribution of the respondents by type of drugs [17] used shows that majority $26.2 \%$ Glue, Cannabis 23.8\%, Sleeping pills 21.4\%, Hashish $9.5 \%$, Bhang $4.8 \%$ and $4.8 \%$ were taking phensydyl (Table 2).

\begin{tabular}{|c|c|c|c|}
\hline $\begin{array}{c}\text { Type of drug } \\
\text { used }\end{array}$ & \multicolumn{2}{|c|}{$\begin{array}{c}\text { Sex of the } \\
\text { respondent }\end{array}$} & \multirow{2}{*}{$\begin{array}{c}\text { Total } \\
\text { (\%) }\end{array}$} \\
\cline { 2 - 3 } & Male & Female & \\
\hline Cannabis & 8 & 2 & 23.8 \\
\hline Hashish & 4 & 0 & 9.5 \\
\hline Bhang & 2 & 0 & 4.8 \\
\hline Liquor & 4 & 0 & 9.5 \\
\hline Sleeping pills & 9 & 0 & 21.4 \\
\hline Phensydyl & 2 & 0 & 4.8 \\
\hline Glue & 9 & 2 & 26.2 \\
\hline Total & 38 & 4 & 100 \\
\hline
\end{tabular}

Table 2: Distribution of the respondents by type of drugs used.

Among the respondents $28.6 \%$ were taking drugs for giving company to their friends, $23.8 \%$ to remove frustration, $9.5 \%$ to alleviate tension, $19 \%$ for having good feeling when taken and $4.8 \%$ due to family trouble (Graph 18).

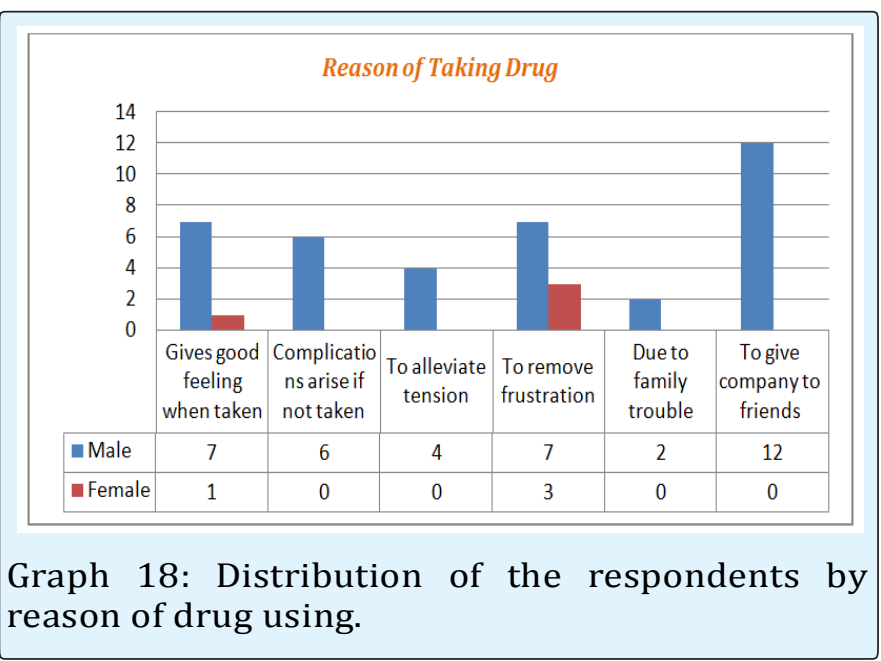

About sexual experience, majority (53\%) had this experience: among them all the female street children were included (Graph 19). 


\section{Open Access Journal of Microbiology \& Biotechnology}

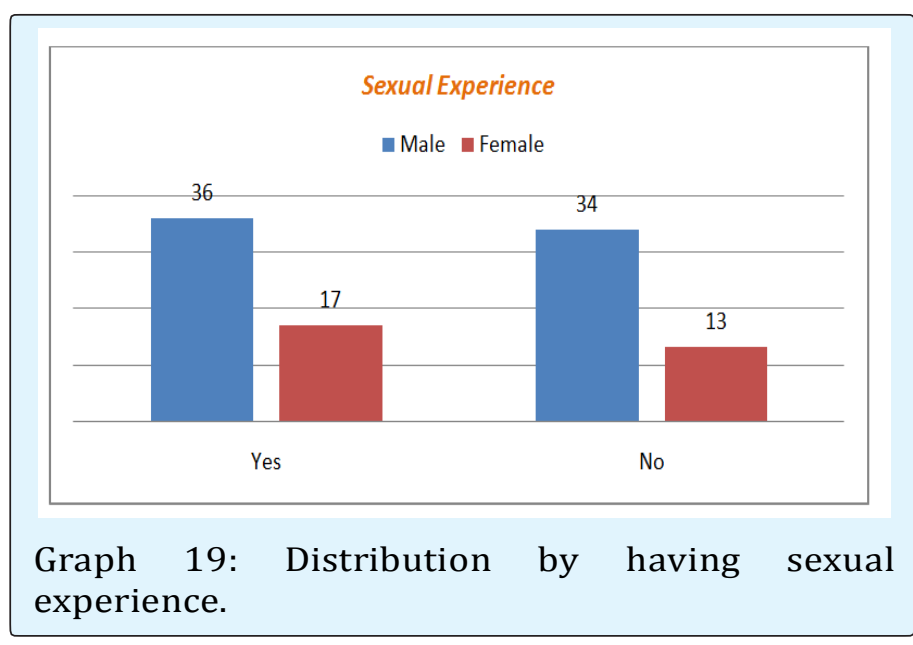

Among the 53 respondents $37.7 \%$ had first sexual experience at or below 12 years and $62.3 \%$ at or above 13 years of age (Table 3 ).

\begin{tabular}{|c|c|c|c|}
\hline \multirow{2}{*}{$\begin{array}{c}\text { Age at first sexual } \\
\text { experience in group }\end{array}$} & \multicolumn{2}{|c|}{$\begin{array}{c}\text { Sex of the } \\
\text { respondent }\end{array}$} & \multirow{2}{*}{$\begin{array}{c}\text { Total } \\
\text { (\%) }\end{array}$} \\
\cline { 2 - 3 } & Male & Female & \\
\hline$<=12$ Year & 8 & 12 & 37.7 \\
\hline$>=13$ Year & 24 & 5 & 62.3 \\
\hline Total & 36 & 17 & 100 \\
\hline
\end{tabular}

Table 3: Distribution by age at first sexual experience.

Among the respondents $32.2 \%$ were reported that they were harassed by unknown person, $16.9 \%$ by police, $11.3 \%$ by friends, and $9.4 \%$ by co-worker $7.5 \%$ by relatives and the rest by others.

Among the respondent's $27 \%$ of the street children's were engaging in paper/garbage collection, $7 \%$ were kuli, $10 \%$ had taken their job as selling newspaper, $7 \%$ cleaner in WASA and 3\% were engaging in picking other man's pocket. The rest were involving in begging and selling flowers (Graph 20).

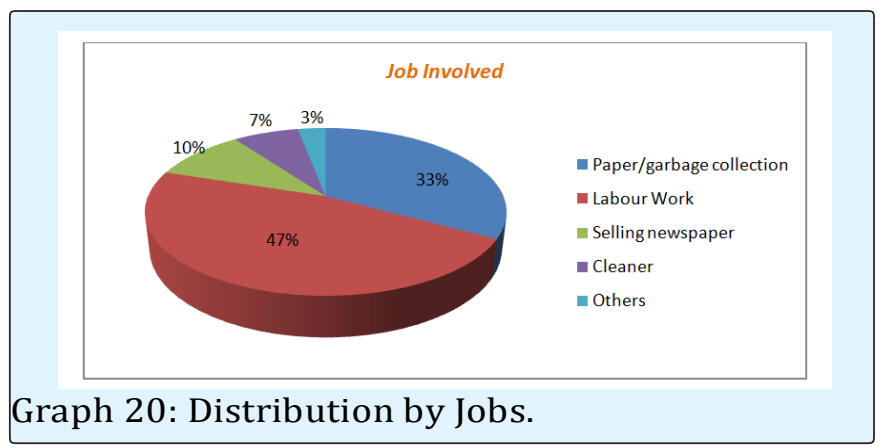

\section{Discussion}

UNICEF defines street children as those who are of the street and on the street. In this study the, term street children refer to those children of 6 to 18 years of age who earn their living on the streets and stay there for most of the time. They may or may not have parents or legal guardians. This cross sectional study was conducted among the street children of Dhaka city with the objectives to determine the magnitude of risk behaviors among them. Data was collected by face to face interview using semi-structured questionnaires $[18,19]$.

The study showed that the parents of the $53 \%$ respondents live outside Dhaka city. The main reasons they left their parents were poverty, presence of step parents, for earning money, run away with friends and physically abused by family members. Natural disasters, river erosion, flood, famine and rising water level affect most of the children of poor and marginalized families. A large number of children are driven to the capital city and other towns for their survival as they face immense suffering due to broken family and natural calamities and take shelters in the streets in different cities and towns.

Many of these vulnerable street children are being picked up by criminals for keeping arms, throwing bombs at targets, selling drugs, and pilferage of food grains for small amount of money. These children also adopt new techniques such as asking monetary help from the passersby in the name of treatment for their sick family members. Often they spoil the money earned through hard labour by taking drugs.

The major problem of the street children are insecure life and physical and sexual abuse by adults of the immediate community. Poverty, family disintegration, negligence, abuse or abandonment and social unrest are the common triggers for a child's life through on the streets and becoming vulnerable to all forms of exploitation and abuse.

Mortality and morbidity status among the street children reached on alarming level due to lack of basic health care services. They remain beyond health care facilities. The disadvantaged street children are most vulnerable to various 
complicated diseases because of overcrowding, poor environmental status and unhygienic food stuffs.

Hunger compels the street children to take most odd jobs and even criminal activates. So an alarming incidence of negative mental and physical health outcomes like depressed anxiety and greater level of antisocial and violent behaviors has been observed. The study revealed that most of the street children had the experience of being abused by family members, other relatives, police or mastans. Other than police the street mastans regularly abused them and took away their hard earned money by threatening them.

In fact people in our society are not much concerned about the addiction among street children because they are keep out of sight and so are out of mind. The direct impact of the problem is that by neglecting these children, who will soon become adolescents and teens, Bangladesh will lose a portion of her young work force, we will lose our potential resources and they will become a national burden.

Consistent abuse and inhumane treatment are the norm for the street children. They are extremely vulnerable to sexually transmitted disease including HIV/AIDS. Bangladesh has a high prevalence of STDs which in turn increasing the vulnerability to HIV infection. Therefore, it is required to take preventive steps for these unfortunate children.

\section{Conclusion}

Among the urban people in Dhaka city, street children are the most vulnerable. They are surviving by recycling rubbish, begging, or doing any of odd jobs that would earn them some food. Children's rights are at best ignored and at worst trampled upon through indifference, economic exploitation, and sexual and physical abuse. The finding of this study suggests that the street children are extremely vulnerable in terms of their health needs and health care.

They are practicing an unhygienic life style. They are most vulnerable to diseases and adverse environmental conditions, with no assistance or guidance on how to maintain a well balanced diet.
Street children are often exposed to, and have easy access to non-prescriptive drugs, such as alcohol, tobaccos, sniffing glue/petrol--- they use this substance to relieve hunger and this lead to malnutrition [20-23]. Exploitation, harassment, and abuse, both physical and verbal including sexual abuse are the major sufferings of the street children. Poverty pushes them many anti-social and violent activities.

\section{References}

1. Mohammad Anwaruddin (2007) Health Risk Behavior of street adolescents in Dhaka city (Dissertation) NIPSOM.

2. Niaz Ahmed Khan (2008) Report "Educating street children" The Daily star, Bangladesh.

3. (2008) Bangladesh News (Online Publication); Plight of our street children.

4. UNICEF (2006) The state of world's children.

5. Uddin MJ, Koehlmoos TL, Ashraf A, Khan AL, Saha NC, et al. (2009) Health Needs and Health care-seeking behaviour of street-dwellers in Dhaka, Bangladesh. Health policy plan 24(5): 385-394.

6. (2000) Exploitation of children- A world outrage. Casa Alianza, Newyork, USA.

7. (2010) Child Malnutrition. Restless Beings, UK.

8. Nahar N, Ahammed I, Milkey SA, Chowdhury SM (2000) The status of street children of Dhaka metroplitan area \& their vulnerability to STD/HIV/AIDS. Int conf AIDS 9-14.

9. Jesmin Akter (2009) Health and living conditions of street children in Dhaka city.

10. Shamsul IK (2008) Health Needs and Health seeking Behaviors of street duelers in Dhaka city. ICDDR.

11. WHO (2000) Working with street children, World Health Organization.

12. Shahnaz Parveen (2008) World street children News: Bangladesh street kid News.

13. (2009) Situation Assessment and analysis of children and women in Bangladesh. UNICEF, Bangladesh. 
14. Chowdhury S (2007) Life style of street children and their risk behavior (Dissertation).

15. (2008) News and Events of street dwellers, health in Bangladesh. ICDDR.

16. Kabir ASZ (1993) A study of Assessment of the Health care Needs of street adolescents of Dhaka City (Dissertation) Health Education NIPSOM.

17. Rey DM (2000) Street children and drug Abuse: Social and Health consignee; WHO, NIDA, California, 17-19.

18. Nergis $T$ (2002) Social Influence in Health Risk Behaviors of Male adolescent college students of Dhaka city (Dissertation) NIPSOM.
19. Ahmed TAH, Islam M, Akter N (2007) Street child workers; Behavioral risk factors for HIV/AIDS and sexually transmitted Infection.

20. The Unconvention: On the Rithts of child, Legal definition.

21. Slap GB, Jablow MM (1994) Teenage Health Care (Edn1), An original publication of pocket book.

22. Friedman BS, Fisher M, Schonbery KS, Alderman ME (1998) Comprehensive adolescent Health care. (Edn2), Maple vial book manufacturing group, USA.

23. Mohammad Khairul Alam (2009) HIV risk Behavior Depend on teen knowledge of sexuality. 